\title{
Los vacíos de Sefarad. La memoria del Holocausto en España ${ }^{1}$
}

\section{The Voids of Sepharad. The Memory of the Holocaust in Spain}

\author{
Alejandro BAER \\ Universidad de Bayreuth \\ a.baer@uni-bayreuth.de
}

Recibido: 10.11 .2010

Aprobado definitivamente: 03.06.2011

\section{RESUMEN}

Aunque España no tenga una conexión inmediata con el Holocausto en términos históricos, las temáticas en torno al genocidio de los judíos europeos durante la Segunda Guerra Mundial tienen una presencia creciente en el discurso público español. Las razones de esta irrupción del Holocausto en ámbitos políticos, educativos y culturales pueden encontrarse en la convergencia político-institucional con Europa, pero también en el debate en torno a la memoria histórica del franquismo y el legado de sus crímenes. Partiendo de las teorías sobre las memorias colectivas cosmopolitas y transnacionalizadas (Levy y Sznaider, 2002; Jeffrey Alexander, 2002; Huyssen, 2002) este ensayo aborda la memoria, o las memorias, del Holocausto en España. La significación globalizada del Holocausto da pie a que este acontecimiento sirva de matriz interpretativa de experiencias traumáticas propias, permita proyecciones y equiparaciones muy diversas, y desencadene significativos rechazos y resistencias. En este sentido, el ensayo plantea también que el desafortunado vínculo histórico con lo judío en España, cuyas secuelas son todavía manifiestas, también condiciona las formas de recordar el Holocausto en la España contemporánea.

Palabras Clave: Holocausto, memoria, genocidio, Guerra Civil, España, conmemoración, antisemitismo.

\begin{abstract}
Spain is a country with no immediate historical connection to the Holocaust. However, in recent years discussions about the Holocaust have gained a more significant presence in Spain's public life. This irruption of the Holocaust in the spheres of politics, education and culture can be explained as a consequence of

\footnotetext{
${ }^{1}$ Una versión previa de este artículo fue publicada en inglés en el monográfico "Revisiting Jewish Spain" del Journal of Spanish Cultural Studies (Vol. 12, No. 1, marzo de 2011, pp. 95- 120). Agradezco a los editores del número especial de esta revista (Tabea Linhard, Daniela Flesler y Adrian Pérez Melgosa) sus comentarios, críticas y sugerencias al texto. Igualmente quiero agradecer a ballido, entre otros - por el estimulante debate en torno al análisis de los rituales de recuerdo del Holocausto en España. Este artículo drid, Plan Nacional I+D+i - Ministerio de Ciencia e Innovación (FFI2009-09368).
} los integrantes del Taller de Videoanálisis de la Facultad de Ciencias Políticas y Sociología — especialmente a los profesores Bernt Schnettler, Esmeralda Ballesteros, Maria J. Velasco y Enrique Garcia, y a los alumnos Elena Herrera, Laura Barragan y Daniel Carforma parte del proyecto "Filosofía después del Holocausto: Vigencia de sus lógicas perversas", Instituto de Filosofía (CSIC) - Ma-
\end{abstract}


political and institutional convergence with Europe as well as of the growing debate over the memory of the crimes of the Franco dictatorship. Using as its basis theories of cosmopolitan and transnationalized memories (Levy y Sznaider 2002, Jeffrey Alexander 2002, Huyssen 2002), this paper approaches the memory, or the memories, of the Holocaust in Spain. The globalized significance of the Holocaust permits different groups to define their own traumatic experiences by creating parallels with the Holocaust, it allows projections and comparisons of different types, and triggers significant resistances and rejections. This essay also argues that the unfortunate historical link to everything related to Jews in Spain, the effects of which are still present, shapes the ways the Holocaust is remembered in contemporary Spain.

KeY words: Holocaust, memory, Genocide, Civil War, Spain, Commemoration, anti-Semitism.

\section{SUMARIO}

1. España y el Holocausto: tan lejos y tan cerca. 2. Historia de una memoria invisible. 3. Entre la instrumentalización y la "envidia de memoria". 4. El "Holocausto español": el nazismo como paradigma. 5. Un "tic" español: el Holocausto en Palestina. Conclusión: la huella de Sefarad. 
En España el Holocausto fue "un tema de judíos y de alemanes" hasta bien entrada la democracia. España no solo no vivió la tragedia del Holocausto en su territorio sino que, fundamentalmente, permanece sumida en su drama interior y aislada del trauma moral europeo. Cuando recupera la democracia lo hará en los márgenes del sistema de valores europeo - en el que la memoria de Auschwitz ocupa un lugar central. En la última década España se incorpora progresivamente, mediante iniciativas institucionales como las ceremonias conmemorativas o los efectos de la transnacionalización cultural y educativa, a esta cultura de la memoria netamente europea. Pero lo hará lastrando las ataduras y silencios que siguen pesando sobre su propio pasado, así como un denso manto de desconocimiento y persistentes prejuicios en torno a la temática judía.

Diversos sociólogos han planteado que el Holocausto se ha convertido en una memoria globalizada y cosmopolita (Levy y Sznaider, 2002; Alexander, 2002), es decir que el vínculo con este pasado va más allá de los colectivos o las naciones afectadas o responsables, trascendiendo los estables marcos sociales que para Halbwachs (1968) configuran las memorias colectivas. Según sostienen estos autores, el recuerdo global del Holocausto se configura en un imperativo político y moral universal en torno a valores como los derechos humanos, la tolerancia y el pluralismo, que son compartidos por individuos más allá de barreras nacionales, étnicas o culturales. Al mismo tiempo, el Holocausto se convierte en una metáfora proyectiva invocada con cada vez mayor frecuencia en conexión con otros eventos trágicos del pasado o el presente. La sociedad española no tiene una conexión inmediata, en términos históricos, con el Holocausto pero ha entrado en contacto con la significación simbólica del mismo y hoy emergen múltiples discursos sobre el Holocausto en distintos contextos, que reproducen parámetros trasnacionales y contienen especificidades nacionales y locales. Igualmente, distintos grupos han comenzado a codificar experiencias traumáticas propias así como realidades políticas distantes, construyendo equivalencias con el Holocausto.

\section{ESPAÑA Y EL HOLOCAUSTO: TAN LEJOS Y TAN CERCA}

La pregunta sobre si el Holocausto concierne a España remite a un conjunto de problemas conceptuales en que se entrecruzan argumentaciones históricas, políticas y filosóficas. Una primera aproximación histórica, estrictamente apegada a los hechos genocidas, arrojaría una respuesta negativa. Como es sabido, no hubo deportaciones de judíos desde suelo español. Tampoco se establecieron leyes raciales. ${ }^{2}$ Los principales enemigos de Franco eran el amplio espectro ideológico de simpatizantes de la República, principalmente socialistas, comunistas y masones. Aunque el dictador español los equiparaba muchas veces con los judíos - como en el conocido "contubernio judeo-masónico-comunista"- el antisemitismo retórico del régimen se diferencia del radical antisemitismo racial que fue el eje central de la ideología nacionalsocialista. Esto explica que tampoco se aplicara una discriminación formal entre refugiados judíos y no judíos, quienes a partir de la caída de Francia en verano de 1940 se agolpan en la frontera pirenaica para atravesar España rumbo a Portugal y América. El criterio dominante seguido por el régimen fue político: impedir el paso a los enemigos de la Causa Nacional y mantener el número de refugiados dentro del país lo más bajo posible.

En este primer sentido la distancia respecto al Holocausto es clara. Ésta se acorta si consideramos que la Guerra Civil y el primer franquismo se sitúan en el contexto general de la segunda Guerra Mundial. La afinidad ideológica, cooperación económica y militar de Franco con el fascismo italiano y el nazismo alemán comienza con la propia ayuda de Hitler al bando nacional en la Guerra Civil española. Franco retribuye los favores durante la guerra mundial, con el suministro de materias primas para la industria armamentística y el envío de la División Azul, por la cual pasaron 47.000 hombres entre 1941 y 1943, los cuales combatieron junto a soldados alemanes y con uniforme de la Wehrmacht en el frente oriental contra el enemigo soviético. También el destino de los republicanos españoles refugiados en Francia estuvo directamente ligado a la guerra mun-

\footnotetext{
${ }^{2}$ La población judía en España es muy reducida en ese momento. Según Haim Avni (1982) no superan las 6000 personas en 1936. La guerra civil y las fluctuaciones de población refugiada dificultan las estimaciones posteriores a esta fecha.
} 
dial y los crímenes del nazismo. Cuando la Alemania de Hitler ocupa Francia en 1940, miles de refugiados republicanos españoles quedan en manos del régimen colaboracionista de Vichy. Después de que el gobierno de Franco se negara a reconocerlos como súbditos nacionales, 9000 españoles —en su mayoría combatientes republicanos que se alistaron en el ejército galo, en la resistencia o en los comandos militarizados de trabajadores - fueron deportados a campos de concentración alemanes, principalmente Mauthausen en Austria. 5000 perdieron la vida en ellos. La significación de los crímenes del nazismo en la memoria española - la republicanaes indiscutible.

Por último, cabe trazar un tercer vínculo entre España y el Holocausto, menos articulado en términos históricos inmediatos aunque de mayor calado filosófico. Como señala Miguel Marinas (2000), lo sucedido a los judíos en Europa nos concierne en España por la memoria de Sefarad, la España judía que desapareció en el siglo XV. La estigmatización, exclusión, persecución y diáspora de los judíos de la Península supone un antecedente del crimen nazi. Más específicamente podemos encontrar un antecedente en la discriminación de los conversos en función de las leyes (raciales) de limpieza de sangre (Stallaert, 2006). Pero fundamentalmente el Holocausto nos concierne por la significación de la memoria de Sefarad — este vacío- en el presente. En otras palabras, no es solamente la conexión FrancoHitler en el contexto europeo lo que nos vincula al Holocausto, sino el hecho de que en la España de Franco y mucho más allá de la dictadura, el genocidio nazi fuera considerado un tema "de judíos y alemanes". "¿Cómo pensar que eso no nos afecta - escribe Reyes Mate- cuando tantos españoles fueron educados en una España franquista, es decir, con categorías que privaban de significación a esta catástrofe?" (Mate, 2006: 13). En este último senti- do la negación de la España judía de nuestro pasado más reciente es un elemento de reflexión fundamental sobre las causas de la "distancia" española respecto al Holocausto. Y este vacío en torno a Sefarad y la memoria judía española también explica y condiciona las formas de recordar el Holocausto en la España contemporánea.

\section{HISTORIA DE UNA MEMORIA INVISIBLE}

"España, imbuida de su espíritu cristiano y universal de amor a todas las razas de la tierra contribuyó al rescate de judios y procedió más por intereses espirituales que por razones políticas o simplemente jurídicas. La ayuda de nuestro gobierno no sólo se extendió a los sefarditas dispersos por los continentes, sino también a todos los judios cuando se presentó la ocasión, sin considerar su nacionalidad o el lugar en que se hallaban"

España y los judíos, Oficina de Información Diplomática, 1949, p.15.

Con el fin de fortalecer su posición internacional en la posguerra mundial, el régimen de Franco se esforzó por difundir en el exterior una cara distinta a la que se le atribuía en relación a su vinculación pasada con la Alemania nazi. En este periodo se construye una imagen idealizada de la actitud y acción de España durante los años de la persecución y genocidio de los judíos en Europa. ${ }^{3}$ Otro mito que se instaura firmemente durante la dictadura es el de la neutralidad española durante la guerra mundial, cuando en realidad Franco mantuvo una doble posición de abierto simpatizante con la causa nazi y, por otro lado, de cauto país no-beligerante frente los aliados occidentales (Avni, 2003, Rother, 2004). Ambos mi-

\footnotetext{
${ }^{3}$ La realidad histórica es notablemente distinta. El gobierno de Franco actuó de acuerdo a una razón de Estado que dictaba una implicación mínima en el salvamento de judíos en el periodo de máxima urgencia (entre 1942 y finales de 1944). Consignas de pasividad dadas a los diplomáticos, limitación de beneficiarios de la nacionalidad española y medidas dilatorias en lo concerniente a las repatriaciones fueron los rasgos de esta política oficial. Los protegidos y salvados del exterminio deben su existencia a la iniciativa y determinación de los cónsules que a título individual intercedieron por ellos y, también, a la evolución de la guerra. En la medida que la balanza se inclinaba hacia la victoria aliada, fue más fácil convencer al gobierno de España para que accediera a la repatriación de los judíos con nacionalidad española — que no fue tal, sino más bien una operación de asilo y tránsito—, y también para que fuera flexible respecto al paso clandestino de refugiados por la frontera pirenaica. Ver Rother, 2004, Ovni, 1982, Marquina y Ospina, 1987, Baer, 2009.
} 
tos perduraron por décadas, aunque siempre se proyectaron hacia fuera. Hacia adentro tanto la Guerra Mundial como los judíos asesinados —o supuestamente salvados - durante el Holocausto eran un asunto distante y desconocido, principalmente porque, como señala Álvarez Chillida durante el régimen de Franco "Alemania seguía apareciendo en el lado bueno en el gran combate contra el comunismo" y "el genocidio judío se ocultó todo lo que se pudo, que fue mucho" (2002: 420). ${ }^{4}$ El recuerdo de las víctimas republicanas de los nazis quedó expresamente prohibido. En 1962 se funda en la clandestinidad la asociación Amical de Mauthausen, que agrupa a exiliados republicanos que sufrieron la deportación a campos nazis, y no consigue su legalización hasta 1978. ${ }^{5}$ Jorge Semprún, detenido en Francia y deportado a Buchenwald por pertenecer a la Résistance, publicó su testimonio Le grand voyage en París, en 1963. En España aparece la traducción —El largo viaje - tras la muerte del dictador en 1976. En este contexto, el recuerdo de los crímenes nazis queda en la memoria colectiva de los grupos de víctimas inmediatas: los antiguos deportados republicanos y la pequeña comunidad judía española(y aquí fundamentalmente aquellos de origen europeo y afectados directamente por la tragedia, dada la composición de esta comunidad, que hasta los años 80 es fundamentalmente sefardí de origen marroquí).

¿Cambiarían las cosas con la llegada de la democracia? Como es sabido, España se diferencia de otras transiciones posteriores en América Latina o por ejemplo Sudáfrica porque aquí se optó por lo que unos han denominado "echar al olvido" el pasado (Juliá, 2003) y otros el "pacto de silencio", es decir el olvido más o menos voluntario del pasado como pacto para asegurar el futuro. Se pasaba de la dictadura a la democracia instaurando una cultura política del consenso y la reforma, que preconiza el olvido en nombre del entendimiento y la paz, más allá de cualquier consideración de justicia. No se produce un relevo substantivo en la estructura de poder, y ni siquiera hay cambios en el plano de los símbolos. Los monumentos, estatuas y placas del franquismo - como las erigidas "los caídos por Dios y por España"-, perdurarán por años, y algunos incluso décadas, tras la muerte del dictador. Igualmente, las monedas con la efigie de Franco son retiradas muy lentamente de la circulación, y seguirán de curso legal hasta la llegada del Euro en 2000. En este contexto, ni los republicanos deportados ni Auschwitz tienen espacio alguno, ni siquiera en los libros de texto. ${ }^{6}$ Como señala Antonio Muñoz Molina (2006: 11), "la historia proscrita por el franquismo fue una historia simplemente abandonada por la democracia".

Hay, no obstante, un conjunto de factores coyunturales y en su mayoría externos que configuran un marco sociocultural en que la temática del Holocausto tiene progresiva acogida, aunque solamente podemos aquí señalarlos de forma muy esquemática. España ingresa en la Unión Europea en 1986 y en ese año también establece relaciones diplomáticas con Israel. En torno al quinto centenario de la expulsión en 1992 se producen una serie de iniciativas culturales sobre el pasado judeo-español. ${ }^{7}$ Las transiciones en el Cono Sur latinoamericano despiertan el interés en España y, más tarde, la implicación de jueces españoles en la persecución a militares con cargos por crímenes contra la humanidad en Argentina y en Chile ocupa portadas y debates en los medios. Asimismo, lo hacen el genocidio y las limpiezas étnicas (Balcanes, Ruanda) y las noticias europeas sobre restituciones a supervivientes y trabajadores esclavos del nazismo. En 1997 se crea la "Comisión de Investigaciones de las Transacciones de Oro procedente del III Reich durante la II Guerra Mundial", que tenía como misión esclarecer una posible implicación del gobierno de Franco en el lavado de dinero y objetos de valor procedente de víctimas del nazismo. Pero el tema no da lugar

\footnotetext{
${ }^{4}$ Destaca este historiador la censura cinematográfica ejercida durante décadas contra todo lo que significara una crítica severa al régimen de Hitler y señala que las imágenes del exterminio — como las que aparecen en la película de Stanley Kramer Judgement in Nuremberg (1961) (titulada en Espana como Vencedores o vencidos) — permanecieron vedadas hasta prácticamente el final de la dictadura.

${ }^{5}$ Ver "Amical de Mauthausen y otros campos de concentración nazis." <www.amical-mauthausen.org>

${ }^{6}$ En mi libro de bachillerato de Historia Contemporánea aparece solamente una breve mención a los "seis millones de judíos exterminados" en un apartado del capítulo sobre la guerra mundial titulado "repercusiones demográficas" (Fernández, 1988: 370).

${ }^{7}$ Sobre las relaciones España-Israel ver Lisbona (2002). Sobre los Actos del Quinto Centenario ver Rozemberg (2006).
} 
al importante debate que generó en otros países y quedó zanjado anticipadamente por un una comisión muy cuestionada, cuyo informe final sostenía, en contradicción con lo que apuntaba el informe Eizenstat, que las compras españolas fueron "jurídicamente impecables". 8

Es fundamental subrayar que el Holocausto llegaría al gran público a través de las películas americanas y europeas que se han ocupado (para desazón de muchos) de este tema. La serie Holocausto se emite en 1979 en la televisión estatal española y supone la primera gran repercusión mediática, aunque el tema tiene su apogeo en los años 90. En 1994 se estrena con gran éxito La Lista de Schindler y en 1998 La vida es bella. Igualmente, los numerosos documentales y reportajes en el 50 aniversario de la liberación de los campos y el final de la Segunda Guerra Mundial acercan la historia del genocidio nazi a amplias audiencias. En este contexto también sale a la luz mediática Violeta Friedman (1997), superviviente de Auschwitz residente en Madrid. En el transcurso de una larga batalla judicial contra el nazi belga León Degrelle, Friedman inicia también una comprometida lucha por la difusión de la memoria del Holocausto y contra el negacionismo neonazi en televisiones y radios, asociaciones antirracistas, universidades y colegios. El caso Violeta Friedman vs. León Degrelle señalaba además un hecho sobre el que pocos habían reflexionado hasta el momento: la presencia e impunidad de criminales nazis en España desde el mismo final de la guerra mundial.

A partir de 2000 se produce un progresivo y muy significativo cambio en lo que respecta al interés por la Guerra Civil y el franquismo en España. El detonante es un heterogéneo movimiento cívico de enorme vitalidad organizado en torno a la llamada "recuperación de la memoria histórica", que sostiene que el olvido durante la transición de las víctimas del bando republicano supone una grave traición en términos éticos y políticos, cuyas consecuencias revierten negativamente en la calidad democrática del presente. ${ }^{9}$ El cuestionamiento sobre las políticas de la memoria y la acusación de una generación a la anterior de haber cerrado en falso el pasado revela, como señala Francisco Ferrándiz (2007), carencias significativas en la gestión colectiva del recuerdo. Este cambio en la sensibilidad social por la memoria y el rebrote de los debates en torno a la naturaleza y significación del pasado traumático revierten en el interés por el Holocausto y éste, a su vez, en la medida que se ha ido haciendo presente en la década anterior en el plano de los medios, la cultura y la investigación, ${ }^{10}$ afecta manifiestamente a los debates sobre la memoria de España. Veremos que no hay un punto de encuentro o de confluencia único sino que emergen múltiples discursos sobre el Holocausto y de apropiación, comparación y proyección del Holocausto en diferentes contextos.

\section{CONMEMORACIONES: DEL YOM HASHOAH AL 27 DE ENERO}

Al igual que otros muchos países europeos, hoy queremos sumarnos al recuerdo del Holocausto, de la "Shoah", al profundo dolor y más firme repulsa de la Humanidad ante el brutal exterminio de tantos millones de seres humanos, que golpeó nuestra propia esencia como personas. Y lo hacemos con el alma de esta

\footnotetext{
${ }^{8}$ La comisión de investigación no fue paritaria e independiente sino nombrada unilateralmente y adscrita al Ministerio de Asuntos Exteriores. El Informe Eizenstat de junio de 1998 señalaba que Alemania empleó oro robado de los bancos centrales europeos para pagar, a través de Suiza, a varios países neutrales, entre ellos España, que habían suministrado materias primas para la industria de guerra. También es un hecho documentado que España fue una salida conveniente para las colecciones de arte expropiadas a judíos. La Federación de Comunidades Judías de España envió una carta de protesta al Presidente de Gobierno J.M. Aznar el 10 de abril de 2000 señalando que "deploran el resultado confuso de la investigación" y que la Comisión Gubernamental "ha trabajado de forma superficial en base a un guión previamente establecido" (Boletín Kehilá, noticias comunitarias, mayo de 2000, p. 9). Ver también Benasuly (1999).

${ }^{9}$ El banner que encabeza la web de la principal asociación (Asociación para la Recuperación de la Memoria Histórica) titula elocuentemente: “¿Por qué los padres de la constitución dejaron a mi abuelo en una cuneta?”. La "recuperación” de la memoria se materializa fundamentalmente en la exhumación e identificación de cadáveres de fosas comunes, así como actos, iniciativas culturales e investigación sobre las víctimas del franquismo. Ver: http://www.memoriahistorica.org/.

${ }^{10}$ En los últimos 15 años se publican numerosas novelas de autores españoles relacionadas con el Holocausto (Jorge Semprún, Antonio Muñoz Molina, Juana Salabert, Adolfo García Ortega, entre otros), así como obras literarias traducidas, testimonios de su-
} 
tierra a la que la tradición judia identificó, desde sus más lejanas raíces, como Sefarad

(Rey Juan Carlos I, Acto del Día Oficial de la Memoria del Holocausto y la Prevención de los Crímenes contra la Humanidad, 26 de enero de 2006)

Las conmemoraciones oficiales del Holocausto que empiezan a celebrarse a nivel oficial a partir del cambio de milenio brindan un interesante punto de observación para explorar fricciones, resistencias y múltiples significados asociados al recuerdo del Holocausto en una España todavía haciendo frente a sus propios fantasmas del pasado. España participa en enero de 2000 en el "Foro Internacional sobre el Holocausto" celebrado en Estocolmo, y el gobierno suscribe allí el compromiso junto al resto de los Estados de la Unión Europea de impulsar formas apropiadas de recuerdo y métodos de transmitir información, conocimiento y movilización ética de las generaciones jóvenes. ${ }^{11}$ La firma de este compromiso no pasa de ser un gesto protocolario carente de consecuencias tangibles en España. El Foro de Estocolmo da lugar, sin embargo, a que las instituciones judías de Madrid, bajo la iniciativa de la Asociación Cultural Hebraica Madrid, propongan la celebración por vez primera de un acto público de recuerdo del Holocausto, en la Asamblea de Madrid. La fecha elegida es el Yom Hashoah ${ }^{12}$ —el 27 del mes de Nissan (a finales de abril en el calendario judío). Comienza entonces entre las asociaciones judías un interesante debate sobre cómo dar forma a esta ceremonia pública y cuál debería ser el lugar en él de las otras víctimas del nazismo. Los organizadores proponen un formato de ritual que quedará como modelo en las conmemoraciones oficiales en Madrid y en los actos de Estado en los siguientes años. Éste se compone de discursos de autoridades (políticos y representantes comunitarios), intervenciones musicales, la oración judía El Maale Rahamim y, como parte central del acto, el encendido de seis velas que, según el formato ritual canonizado por el memorial israelí Yad Vashem (que enciende seis antorchas) y seguido en muchas comunidades judías, simbolizan los seis millones de judíos asesinados durante el Holocausto o Shoah.

La particularidad en este caso está en que la Comunidad Judía concede un espacio en el acto de encendido de velas a republicanos y gitanos españoles. Es decir, que además de quienes representan a la comunidad judía (generalmente supervivientes o hijos de supervivientes, alumnos/as del colegio judío y el Embajador de Israel), un español republicano superviviente de los campos nazis y un representante de una asociación gitana encienden velas "en memoria de las víctimas españolas que murieron en los campos de concentración" y "en memoria de las víctimas del pueblo gitano y de otros colectivos perseguidos por el nazismo". ${ }^{13}$ El mismo acto, de procedencia netamente judía, incorpora así simbólicamente las memorias españolas asociadas al Holocausto. La apertura semántica del término "Holocausto" (ya no entendido como el genocidio judío solamente sino las atrocidades del nazismo en términos más generales) y la adscripción al acontecimiento de sentidos y enseñanzas de corte más universal permite vincular ese pasado a la realidad española - histórica (la República y el fatal destino de sus defensores en los campos nazis) y presente (diversidad de una sociedad multiétnica y multicultural, los "otros colectivos"). Desde 2000, el parlamento de la Comunidad Autónoma de Madrid da cabida anualmente a esta

pervivientes e investigaciones históricas sobre la relación entre el franquismo y la Alemania nazi. Desde finales de los 90 se desarrolla el proyecto de investigación "La filosofía después del Holocausto" (http://www.ifs.csic.es/holocaus.htm), coordinado por el profesor Manuel Reyes Mate en el Consejo Superior de Investigaciones Científicas.

${ }^{11}$ Entre las distintas iniciativas transnacionales ocupa un lugar principal la Task Force for International Cooperation on Holocaust Education, Remembrance and Research (ITF) que existe desde mayo de 1998 -España se incorpora como miembro en 2008. Entre las propuestas europeas están la del Parlamento Europeo, que propone el 16 de marzo de 2000 establecer el 27 de enero como día de conmemoración del Holocausto y la de los Ministros de Educación del Consejo de Europa, quienes resuelven en octubre de 2000 establecer a partir de 2003 un Día de Memoria del Holocausto y de Prevención de los Crímenes contra la Humanidad.

${ }^{12}$ La mayoría de las comunidades judías en el mundo celebran un acto solemne en este día. No hay un único ritual institucionalizado sino que varían considerablemente. Como elementos más comunes suelen incorporar el encendido de velas conmemorativas y el recitado del Kadish o el El Maale Rajamim — oraciones por los fallecidos. También pueden incluir otros elementos como charlas de supervivientes, recitación de salmos o de nombres de víctimas.

${ }^{13}$ Programa del Acto Central de Recuerdo del Holocausto, Yom Hashoah 5760, mayo de 2000. 
ceremonia, aunque el acto se traslada unos años después de abril (Yom Hashoah) al 27 de enero, fecha de la liberación del campo de Auschwitz. El cambio de fecha obedece a un salto cualitativo en las políticas de la memoria del Holocausto en España y es una señal inequívoca de su incorporación al marco transnacional de la memoria globalizada del Holocausto. Dedicaremos a su análisis las siguientes páginas. Durante la segunda legislatura del Partido Popular (2000-2004), las iniciativas de conmemoración del Holocausto partieron de las Comunidades Judías, con acogida oficial muy heterogénea a nivel local y autonómico. Con la llegada al gobierno del Partido Socialista en 2004 será el gobierno del Estado, a través del Ministerio de Exteriores, quien toma un papel más activo y se propone el establecimiento de un día oficial de memoria del Holocausto a nivel nacional. Sin embargo, se planteaba un problema: ¿qué fecha elegir en España para recordar el Holocausto? La preferencia de las comunidades judías por el Yom Hashoah no coincidía con las asociaciones de deportados republicanos, que celebraban anualmente un acto el 5 de mayo, día de la liberación del campo de Mauthausen. El gobierno optó por seguir el ejemplo de otros países europeos y elige el 27 de enero. El simbolismo contenido en la fecha es tan evidente como el mensaje a los colectivos implicados: no se trata ya de recordar la propia historia particular, sino más bien de evocar colectivamente este símbolo europeo y global del mal absoluto - Auschwitz- y proyectarlo en el discurso cívico sobre el presente. En el Consejo de Ministros del 15 de diciembre de 2004, el gobierno resuelve declarar el 27 de enero el Día Oficial de la Memoria del Holocausto y significativo aditamento-la Prevención de los Crímenes contra la Humanidad. En dicha resolución el gobierno se compromete a promover actividades que hayan de dar contenido a la celebración de dicho Día Oficial.

En un principio, el gobierno propone a la comunidad judía continuar con el formato de la Asamblea de Madrid pero en el Congreso de los Diputados (en la Sala Internacional, contigua al pleno) y convertir- lo en Acto de Estado. Tras crear algunas expectativas erróneas no se abrió la intervención en el acto a representantes de otros colectivos más allá del encendido de las velas. Esto provoca malestar, especialmente entre asociaciones republicanas, quienes amenazan con realizar un acto propio en las puertas del Congreso si no se les deja hablar. La presión surte efecto y finalmente se invita a Enric Marco, el octogenario Presidente de la principal asociación, la Amical de Mauthausen, a pronunciar un discurso. Pero ahora será el contenido el que enciende los ánimos, especialmente de los supervivientes y audiencia judía, cuando Marco alude en su discurso a "los campos de concentración del presente", entre los que señalaba Guantánamo y los "Campos en Palestina" (volvemos sobre el vínculo Holocausto-Israel en el último apartado). El episodio con Enric Marco, su intervención y el posterior escándalo sobre su identidad inventada, ${ }^{14}$ produce algo similar a una ruptura y la Federación de Comunidades Judías de España, anfitriona del acto junto al Presidente del Congreso de los Diputados, decide que en las conmemoraciones futuras en el Congreso de los Diputados no intervenga un ponente republicano.

Es así que a partir de 2006 habrá tres actos oficiales de conmemoración del Holocausto: Asamblea de Madrid, Congreso de los Diputados y el que será el propio acto de Estado, coordinado desde el Ministerio de Justicia y Exteriores, para el que se elige, por sus adecuaciones físicas y simbolismo, el Paraninfo de la Universidad Complutense. ${ }^{15}$ Para este acto se cuenta con el Presidente de Gobierno. Rodríguez Zapatero había asistido en mayo de 2005 a las conmemoraciones del sesenta aniversario de la liberación del campo de Mauthausen, siendo la primera vez que tan alta representación del Estado acompañaba a los supervivientes y colectivos de memoria en esta celebración. También estará por vez primera el jefe de Estado en un acto de esta naturaleza. El conflicto que asomaba era el de juntar al Rey con los republicanos en una misma ceremonia. Por ello los organizadores deciden que intervenga el escritor y ex-ministro de cultura Jorge Semprún, una figura muy respetada y de con-

\footnotetext{
${ }^{14}$ Enric Marco pasará a los medios a los pocos meses cuando se demuestra que su testimonio es falso y que no había estado en un

${ }^{15}$ Entrevista con Henar Corbi, entonces Asesora de la Dirección General de Asuntos Religiosos del Ministerio de Justicia y representante ante la ITF. Coordinadora de los Actos de Estado desde 2006. campo de concentración nazi. Ver "El deportado que nunca estuvo all'́," El País, 11 de mayo de 2005, p.72.
} 
senso. Dada una repentina enfermedad Semprún no puede acudir pero envía un texto. El que se eligiera al Rector de la Universidad Complutense, Carlos Berzosa, para leer el discurso, responde a una misma precaución. No querían un representante republicano por temores a que añadiera al texto algún lema poco propio en presencia del Monarca o, como en el año anterior, diera lugar a nuevos roces con la comunidad judía. Por otro lado, la presencia del Rey es un problema para las asociaciones republicanas. Es muy reveladora la formulación que elige el Rey en su discurso para referirse a las víctimas republicanas, pero evitando la palabra. "Hoy no podemos dejar de reservar, como españoles una mención especial al emocionado recuerdo que merecen los miles de hijos de España, que tanto padecieron y a quienes vilmente les fue arrebatada la vida en aquellos campos del horror". ${ }^{16}$

Por lo demás, el acto tiene un formato similar a los anteriores. En este caso participa también el superviviente judío de Salónica Jack Stroumsa, el llamado "violinista de Auschwitz", quien toca la canción judía Eli, Eli (Mi Dios), y otro músico que interpreta en su violín la melodía del Chants de Marais (himno emblemático de los deportados políticos), y un cantante gitano canta a capella el himno internacional gitano Gelem Gelem. La mesa central del acto está presidida por el Presidente de Gobierno, el Rey y la Reina y Jacobo Israel Garzón, presidente de la Federación de Comunidades Judías de España. Estas figuras reunidas en un acto de conmemoración del Holocausto son una estampa inédita en la España contemporánea y suponen un hito significativo en esta historia de la memoria del Holocausto. Con el cruce de memorias judía-republicana —en este caso resuelta con sensibilidad y tacto por ambas partes - y el encuentro de las dos Españas bajo el lema de "hijos de España" se había producido un acto de entendimiento y memorias compartidas. En este acto se rendía homenaje al más alto nivel a las víctimas de la Shoah y a las víctimas españolas en los campos de concentración. El hecho es revelador y en cierta medida paradójico: la memoria del Holocausto (judío) abre el reconocimiento institucional de las víctimas republicanas.
En 2007 el motivo central de la ceremonia es el de las memorias judías españolas: Sefarad. En su discurso del año anterior el Rey había mencionado esta palabra plena de evocaciones en el imaginario judío, aunque muy difusa en el español. Ahora había que darle forma y los coordinadores invitaron al acto en Madrid a 14 sobrevivientes judíos de los campos de los cuales 12 eran judeoespañoles. Se trataba ahora de avanzar en la comprensión de lo que es el Holocausto a partir de una historia tan propia como desconocida: los judíos hispanohablantes y de origen peninsular. Esta idea de los orígenes y éxodos de los judíos de Sefarad se materializa también con la participación en el acto de Estado de rabinos y cantores - jazanim - de distintas tradiciones diaspóricas (Turquía, Marruecos, Argelia, Grecia, Israel) y dos de ellos con el muy español apellido Toledano. En esta ocasión el Rey no participa en el acto pero recibe a los supervivientes en el Palacio de la Zarzuela. El hecho de ser descendientes de los judíos expulsados de España, le da a este encuentro un simbolismo notorio.

En torno al acto de Estado se producen una serie de actividades educativas y culturales que acompañan la orientación y sentido dado a la celebración. El Senado acoge un concierto titulado "Músicas litúrgicas de las diásporas sefardíes del Mediterráneo" y en el Círculo de Bellas Artes de Madrid se celebraron en esa misma semana las jornadas "Transmisión, memoria e identidad. Los judeo-españoles en la Shoá". Cabe mencionar que en este marco se celebraba también la apertura oficial de la Casa Sefarad-Israel, una institución pública española destinada a fomentar el desarrollo de las relaciones con el Estado de Israel y las comunidades y organizaciones judías. En 2007 también se inaugura en Madrid el primer monumento dedicado a las víctimas del Holocausto. ${ }^{17}$

En 2008 España vuelve a conmemorar el Holocausto a través de sus actos oficiales. Entre tanto, diversos Parlamentos Autonómicos se han ido sumando a las iniciativas conmemorativas (Cataluña, Cantabria, Asturias, Baleares, etc.) aunque hay variaciones en su configuración ritual, que obedecen en algunos casos a circunstancias locales o a las diver-

\footnotetext{
${ }^{16}$ Discurso del Rey de España en el acto del Día Oficial de la Memoria del Holocausto y la Prevención de los Crímenes contra la Humanidad, Madrid, 26 de enero de 2006.

${ }^{17}$ La obra del artista judeo-español Samuel Nahón y el arquitecto Alberto Stisin representa una estrella de David y los trenes de la muerte hacia los campos de exterminio. Es también el vínculo simbólico con la mítica Sefarad el que permite interpretar su emplazamiento en el Jardín de las Tres Culturas en el Parque Juan Carlos I.
} 
sas iniciativas de los organizadores. En Melilla, por ejemplo, invitan a la comunidad musulmana, en otros participan representantes de la comunidad Bahai o colectivos homosexuales. Para el acto de Estado en Madrid el motivo elegido en 2008 es, por un lado, Europa y, por otro, la transmisión. En ambos casos, estos conceptos se ponen en directa relación a España en su expresión simbólica. Según los organizadores del acto, si Europa se había reconciliado después del fascismo, España lo hacía después del franquismo. La transmisión del legado de la memoria lo encarnan los niños que tienen este año un protagonismo especial en la ceremonia. Además del formato ya establecido, los discursos, oraciones y el encendido de velas, en esta ocasión se incorpora la lectura de nombres de 27 niños y niñas judías que fueron asesinados durante el Holocausto. Cada uno correspondía a uno de los 27 países que hoy componen la Unión Europea. Otra innovación de este año es la participación de coros infantiles en la ceremonia. El coro del Liceo Francés de Madrid canta el Chant de Marais, el coro del Colegio Judío entonará la popular canción israelí Yerushalaym shel Zahav (Jerusalén de oro), un coro del culto evangélico gitano canta, junto a una solista, el Gelem Gelem $^{18}$ y el coro de la Escolanía de la Abadía de la Santa Cruz $^{19}$ acompaña la lectura de nombres cantando el Salmo 23 y termina el acto con el Himno de la alegría. Los múltiples cruces culturales que escenifican los niños son manifiestos. Desde Europa y los deportados a los judíos, gitanos y católicos. "A los jóvenes se les entrega la llama del recuerdo. Es como decirles: sois europeos porque habéis nacido europeos. Pero tenéis que incorporar en vuestro conocimiento la memoria de Europa". ${ }^{20}$

Llegamos así al año 2009, donde el tema central serán, nuevamente, valores positivos. En este caso, los llamados Justos y el valor de la solidaridad. En esta ocasión el acto viene precedido por un seminario internacional titulado "Luces de humanidad frente al Holocausto", centrado en las lecciones y enseñanzas de individuos que representan ejemplos de actuación moral durante el Holocausto. También aquí es trazado un vínculo directo con España mediante la recuperación de las historias de quienes prestaron ayuda a los refugiados judíos, ya sea en legaciones diplomáticas españolas para la obtención de visados (Rother 2004, Baer 2009) o el paso clandestino por la frontera pirenaica (Avni, 2003, Calvet, 2008). ${ }^{21}$ El acto de encendido de velas simboliza el cruce de memorias y es lugar de encuentro para quienes representan a diferentes colectivos, que en esta ocasión son invitados a encender la vela conjuntamente: niños judíos y gitanos, Justos y salvados, víctimas judías y víctimas españolas.

La figura judía del "Justo entre las Naciones" nos vuelve a plantear la tensión entre memoria particular y universalizada que está presente en la ceremonia desde un comienzo. Al igual que la conocida máxima del filme de Spielberg, ${ }^{22}$ el Justo no es universal en su significación, sino solo mediante una alteración semántica. En la ceremonia, una de las seis velas es encendida "por los Justos entre las Naciones quienes arriesgaron sus vidas para salvar a los perseguidos". Todos los perseguidos, no solo los judíos. Igualmente, la mención al millón y medio de niños judios asesinados, un elemento central en el repertorio simbólico de las conmemoraciones de la Shoah, sufre una pequeña alteración en nombre de la universalidad. La vela es encendida "en memoria del millón y medio de niños asesinados en las cámaras de gas". La palabra "judíos" es omitida.

\footnotetext{
${ }^{18}$ Es interesante observar los efectos de la conmemoración del Holocausto en colectivos como el gitano, llamados a compartir la memoria e invitados a la ceremonia. Para los gitanos españoles la memoria del sufrimiento de su pueblo a manos del nazismo no ha representado un elemento identitario, pero a raíz de las ceremonias del Holocausto comienzan a tomar conciencia de este pasado y de las formas de su articulación en rituales de recuerdo en el espacio público. Plantean ahora por ejemplo, que el Día del Pueblo Gitano no solo sea un acto cultural y también se comienza a hablar del Holocausto y el Porajmos, el genocidio gitano.

${ }^{19}$ La Escolanía de la Abadía benedictina de la Santa Cruz nace en 1958, con la finalidad de contribuir a una mayor solemnidad en las celebraciones litúrgicas de la Basílica del Valle de los Caídos (el mausoleo erigido por Franco en la sierra de Madrid).

${ }^{20}$ Entrevista Henar Corbi, op.cit.

${ }^{21}$ Sobre esto último son de destacar las iniciativas que promueve el Ayuntamiento de Sort (Lérida, Catalunya) desde el año 2000 para recuperación de la memoria de estos acontecimientos. En 2007 inauguró el museo "El Camí de la Llibertat" (http://www.camidelallibertat.cat)

${ }^{22}$ El lema de la película es "Quien salva una vida salva a toda la humanidad". La frase talmúdica original reza sin embargo "Quien salva un solo alma de Israel es como si hubiera salvado a toda la humanidad"
} 


\section{ENTRE LA INSTRUMENTALIZACIÓN Y LA "ENVIDIA DE MEMORIA"}

\author{
"En el museo (de Yad Vashem) no existen \\ apenas referencias a otras etnias y colectivos - \\ gitanos, homosexuales, comunistas, etc.- que \\ también fueron exterminados sistemáticamente por \\ el régimen de Hitler"
}

\section{El País, 13 de septiembre de 2007. ${ }^{23}$}

¿Qué es el Holocausto? ¿El genocidio de los judíos de Europa (la Shoah) o los crímenes del nazismo (1933-1945) en términos más amplios? Por otro lado, si nos quedamos con la primera definición jes el Holocausto singular y único o es un evento comparable con otras atrocidades del pasado y presente? Como ya se ha observado, estas dos preguntas tan recurrentes en el espacio de negociación y conflicto que conforma la memoria globalizada del Holocausto, tienen implicaciones específicas en España.

En Alemania el Historikerstreit (la disputa de los historiadores) puso de manifiesto que el énfasis en la singularidad del Holocausto tiene un componente claramente crítico - ya que cuestiona la identificación de los ciudadanos con una historia nacional. Mientras que poner en perspectiva el genocidio, con los crímenes estalinistas, es necesariamente exculpatorio ("no solo nosotros cometimos atrocidades..."). Sin embargo, para los aliados y simpatizantes de la Alemania nazi, como Italia o España, ocurre el fenómeno contrario: el subrayar la singularidad del Holocausto puede tener efectos exculpatorios respecto al pasado (fascista o franquista). La memoria pública de los crímenes nazis ha sido incómoda para la derecha española (recordemos las dificultades del Partido Popular para desprenderse públicamente de su legado ideológico) porque criminaliza a sus aliados (Franco) y se solidariza con sus víctimas (republicanos) ${ }^{24}$ Los círculos concéntricos que conforman la historia del nazismo y la guerra mundial llegan hasta España, interpelan con fuerza, hoy todavía, en la medida en que ponen el dedo en la llaga de heridas aún no cicatrizadas y pasados "echados al olvido", pero no elaborados. La Shoah en su singularidad, sin embargo, permite sostener una diferencia radical entre nazismo y fascismo - tanto el italiano como el español- y aleja de éste toda sombra del horror. Permite, en definitiva, recordar sin cuestionarse, sin mirar hacia adentro.

Esta paradoja cristaliza en las conmemoraciones. No es casual, por ejemplo que Esperanza Aguirre, Presidenta de la Comunidad Autónoma de Madrid (del Partido Popular), no mencione en sus discursos a los otros colectivos perseguidos por el nazismo, representadas e intervinientes en el acto en el Parlamento Autonómico. En tanto que Shoah y no Holocausto, sólo se homenajean a las víctimas judías (como hace el Estado de Israel y las comunidades judías), dando lugar a una coincidencia de perspectivas que obedece a motivaciones bien distintas. Al mismo tiempo que se silencian las víctimas españolas del nazismo (los republicanos), se encuentran otras equivalencias con el acontecimiento en un plano retórico. Según la perspectiva de Aguirre, los "judíos" de hoy serían quienes sufren la violencia de ETA y el terrorismo vasco encarna a los nuevos "nazis". ${ }^{25}$ En ese mismo acto la Presidenta de la Asamblea, Elvira Rodríguez, situaba la memoria del Holocausto (judía) en directa relación, o mejor dicho en contraposición a su particular concepción del movimiento de recuperación de la memoria histórica: "iniciativas como ésta de la Comunidad Judía no se fundamentan en ningún tipo de sed de venganza o revanchismo, sino en las ganas de recordar conjuntamente el dolor de quienes sufrieron la represión". ${ }^{26}$

Pero además de la evidente instrumentalización partidista, estamos ante un tipo de recuerdo público de nulo potencial crítico. La ejemplaridad remite a

\footnotetext{
${ }^{23}$ Artículo "El Museo del Holocausto de Jerusalén, premio de la Concordia", relativo a la concesión del Premio Principe de Asturias al memorial Yad Vashem.

${ }^{24}$ El Partido Popular rechazó hasta noviembre de 2002 pronunciar una condena pública e inequívoca al golpe militar del General Franco en 1936.

25 "La indiferencia ante el mal absoluto desgraciadamente puede convivir con nosotros. Los ejemplos los tenemos siempre cerca. Solo hay que imaginar la imagen terrible de José Ortega Lara [funcionario de prisiones secuestrado por ETA entre 1996 y 1997] saliendo del agujero donde sus secuestradores le habían tenido más de 500 días y compararla con la naturalidad con la que muchos conciudadanos de aquellos incalificables criminales conviven con ellos, los apoyan o los alientan". Discurso de Esperanza Aguirre en la Asamblea de Madrid, 26 de enero de 2008.

${ }^{26}$ Discurso de Elvira Rodríguez en la Asamblea de Madrid, 26 de enero de 2008.
} 
valores universales pero abstractos, que solo subrayan la "distancia" frente al acontecimiento. Ese "recordar conjuntamente" al que alude la política madrileña es una memoria embalsamada del Holocausto en la que no hay implicación ni responsabilidad alguna. Se habla del antisemitismo nazi y si se alude a la existencia del antisemitismo en el presente será solo como arma arrojadiza contra el adversario político - las derivas de la izquierda antisionista - pero no se menciona, por ejemplo, el papel del catolicismo en la génesis del antijudaismo o a sus pertinaces resabios en la actual iglesia católica española. ${ }^{27}$

Por otro lado, tendríamos el fenómeno contrario, relativo a la mencionada apertura del término Holocausto. Si los republicanos deportados son "víctimas del Holocausto", se pueden establecer precisamente aquellos paralelos entre Hitler y Franco que los usos políticos de la singularización pretenden bloquear. Obviamente, al incluir en el término Holocausto a todos quienes fueron victimas del nazismo se desplaza y diluye la centralidad judía del Holocausto, como debatieron intensamente las organizaciones judías y representantes gubernamentales al diseñar un modelo ritual conmemorativo. Dado el carácter periférico en la historia del Holocausto y el hecho que los republicanos sean el principal grupo de víctimas españolas del nazismo este problema, que no es exclusivo de España, aquí adquiere matices muy específicos. Existe una cierta "envidia de memoria" (Hartman, 2002) por parte de los colectivos republicanos, motivada sin duda por el sentimiento de agravio ante su invisibilidad durante 30 años de democracia. Pero esta envidia de memoria deriva en ocasiones hacia el cuestionamiento de la propia centralidad del Holocausto (el genocidio judío) como objeto de memoria. Esto se produce en la esfera pública - y no tanto por los propios deportados- en el discurso de la memoria republicana más amplio mediante una más o menos explícita acusación del protagonismo excesivo, y en casos también apropiación particularista de la tragedia por parte de las comunidades judías y el Estado de Israel. No se trata, sin embargo, de críticas a interpretaciones judeocéntricas o sionistas del Holocausto sino, como vemos en los ejemplos, de una incomprensión de la especificidad histórica del acontecimiento y la universalidad de sus implicaciones (Auschwitz como una reserva de sentido político, moral, pedagógico).

Las imputaciones sobre un bloqueo o eclipse de otras memorias - en referencia a la del antifascismo- no se sostienen y más bien cabría plantear lo contrario. En España (a diferencia de Francia), en el contexto de una conflictiva negociación sobre el pasado franquista, son paradójicamente memorias judías — en su versión globalizada por la industria cultural y las iniciativas institucionales - las que contribuyen a abrir la puerta a las memorias de la deportación republicana. ${ }^{28} \mathrm{Si}$ existe tal problema, remite en todo caso a una discusión muy europea sobre la asimetría de recuerdos del pasado en el que las memorias del nazismo/fascismo amenazan con bloquear la percepción de los crímenes estalinistas. Esta controversia tiene también una lectura española y se sitúa en los debates sobre la "recuperación de la memoria histórica", en que se lanzan acusaciones cruzadas de relativización del franquismo, por un lado, y de ausencia de autocrítica respecto al llamado "terror rojo" por otro.

Se nos plantea así una situación muy llamativa. La cultura de la memoria europea y globalizada del Holocausto introduce en España un cuerpo extraño, que al mismo tiempo es rechazado y apropiado. Rechazado, porque no hay una conexión inmediata histórica con los acontecimientos a recordar y porque en la cultura política española ha imperado una lógica extraña a la memoria, que sólo en la última década comienza a ser cuestionada. Apropiada en diversas formas de identificación y comparación

${ }^{27} \mathrm{El}$ periodista y escritor Enric Juliana señalaba recientemente que "la jerarquía católica española hizo todo lo posible para desentenderse de la reflexión autocrítica sobre la Shoah emprendida por el Vaticano entre 1998 y 2000: mientras Juan Pablo II pedía perdón en el muro de las Lamentaciones, el cardenal Rouco Varela [entonces presidente de la Conferencia Episcopal Española] planeaba la beatificación de Isabel de Castilla (Isabel la Católica) bajo la atenta mirada de José María Aznar". La Vanguardia, 10 de enero de 2009.

${ }^{28}$ Como plantea Michael Rothberg en su libro Multidirectional Memory (2009), en el ámbito de la memoria del Holocausto no estamos ante un juego de suma cero por la preeminencia en la esfera pública, sino un fenómeno multidireccional, sujeto a negociación constante, referencias cruzadas y préstamos. El Holocausto como memoria global, según este autor, sería un fenómeno esencialmente productivo y no privativo, que incluso ha contribuido a articular otras demandas. 
con la tragedia española, la contradicción principal que introduce la memoria del Holocausto es la que plantean los propios represaliados del franquismo: ¿Recordar el Holocausto y olvidar lo sucedido en España? Lo cuestiona Clarisa, perteneciente a una familia con cuatro desaparecidos en Las fosas del silencio:

No oigo a nadie decir que se olviden del holocausto, que se olviden del tren de la muerte que iba a Auschwitz o a Mauthausen, que se olviden de Pinochet. Sin embargo, en España hubo que correr un tupido velo, olvidar a todos nuestros familiares, olvidar las penas y las angustias. No sé por qué hay que olvidarlo todo y borrón y cuenta nueva. Me parece grotesco querer ser los justicieros del mundo y que aquí no pase nada (Armengou y Belis, 2004: 24)

\section{EL "HOLOCAUSTO ESPAÑOL": EL NAZISMO COMO PARADIGMA}

Si algo caracteriza la llamada globalización del discurso del Holocausto, es que éste pierde su calidad de índice del acontecimiento histórico específico y comienza a funcionar como una metáfora de otras historias traumáticas y su memoria (Huyssen, 2002). En España estas otras historias son las que emergen fundamentalmente en relación a la Guerra Civil y la represión franquista. Exhumaciones de fosas comunes, proyectos de registro y archivo de testimonios de supervivientes, homenajes y conmemoraciones en torno a fusilamientos, prisiones y campos de concentración franquistas, muestran la influencia de la cultura del Holocausto ya que ésta se manifiesta en las inquietudes y formas en que se da expresión a la memoria de la tragedia española. Las imágenes y conceptos del Holocausto y el término "Holocausto" mismamente, junto con el repertorio simbólico asociado a los "desaparecidos" en el Cono Sur (a su vez influido por el Holocausto) constituyen, por así decir, un patrón matricial de las formas varias de producción, circulación y consumo de memoria traumática en los citados contextos (Ferrándiz y Baer, 2008). Es interesante observar como las propias víctimas —en este caso Juana Doñarecurren al topos "Holocausto" en sus testimonios para definir sus vivencias:

La represión franquista fue algo terrible, muy criminal, muy cruel...como lo que vemos en las películas de Hitler. Igual. No nos echaron a los crematorios, pero la gente moría en las cárceles y en los campos de concentración, morían de hambre y suciedad, y de avitaminosis, y de parásitos, morían de todas las crueldades que hay para el ser humano. Fue un holocausto todo lo que nos pasó, y la gente no lo sabe todavía. (Armengou y Belis, 2004: 161)

El paradigma del nazismo y el Holocausto se aprecia también en numerosas obras históricas sobre la Guerra Civil y el Franquismo. “¿Hay un Holocausto español?" es el subtítulo que eligen los autores de Las fosas del silencio, un trabajo basado en testimonios de víctimas de la represión franquista. También la terminología empleada en las imputaciones hechas para juzgar crímenes nazis es empleada para caracterizar las acciones de violencia extrema de las tropas y secuaces franquistas durante y después de la guerra civil española. Javier Rodrigo señala el frecuente recurso en la historiografía sobre el franquismo a los términos "genocidio" u "holocausto" y la propia definición de la Guerra Civil como "guerra de aniquilación" o "de exterminio". ${ }^{29}$ Por ejemplo, Francisco Espinosa considera que la matanza de la plaza de toros de Badajoz en agosto de 1936 supuso un prolegómeno y una premonición de Auschwitz. Ferrán Gallego también plantea que "fascistas alemanes y españoles llevaron a cabo (...) formas de exterminio planificadas de forma más o menos minuciosa" (2008: XII-XIII). Hay que situar el uso de estas analogías en el contexto de una historiografía extremadamente polarizada que recurre a la hipérbole en la medida que no hay consenso sobre los hechos y, sobre todo, sobre las interpretaciones. ${ }^{30}$

\footnotetext{
${ }^{29}$ Javier Rodrigo (2005) sostiene la necesidad de emplear términos más apropiados para el caso español ya que el objetivo de Franco era no tanto exterminar sino sobre todo doblegar y transformar. De ahí que, sin minimizar la violencia extrema que llevaría a tal fin, aboga por el de "política de exclusión", y no de exterminio.

${ }^{30} \mathrm{En}$ los dos bandos enfrentados en la Guerra Civil se recurrió a formas de violencia extrema en la retaguardia, y es muy común en
} 
Equiparar la violencia franquista a la nazi permite subrayar la equivalencia moral de los perpetradores. Además, como señala el historiador Carlos Pabón, en el contexto de la globalización y universalización de la memoria del Holocausto, aquellas matanzas de civiles o atrocidades - ya sean del pasado o del presente- que no obtienen el reconocimiento como genocidio quedarían banalizadas o invisibilizadas. Esta "combinación de moralismo y legalismo" se articula en los usos instrumentales del término genocidio y Holocausto. Son empleadas para enjuiciar pero tienen escaso valor explicativo y analítico.

Es interesante observar cómo la historiografía revisionista, y en ocasiones apologista de Franco, recurre a las mismas analogías para referirse al llamado "terror rojo". Por ejemplo, Pío Moa sostiene que "la persecución de los sacerdotes y muchas monjas, masacrados a menudo con sadismo increíble, se emparenta cualitativamente con el Holocausto perpetrado por los nazis contra los judíos, pues en ambos casos las víctimas eran asesinadas simplemente por ser judíos, o clérigos en el caso español."

\section{UN "TIC" ESPAÑOL: EL HOLOCAUSTO EN PALESTINA}

Los recientes acontecimientos de Gaza nos demuestran que esa capacidad de exterminio (la de la "industria de la muerte" creada por los nazis) no sólo no ha sido erradicada sino que se reproduce una y ota vez (...) Es esa misma fuerza la que nos plantea el deber moral de pedirles, en tanto que organizadores del acto anual de conmemoración de la Shoah, que den cabida y promocionen en los mismos términos un acto en conmemoración de la Nakba (15 de mayo).

(Petición pública del Colectivo "Todos somos Palestina" al Rectorado de la Universidad Complutense de Madrid, mayo de 2009)

Con la cita que encabeza este apartado, de un colectivo de profesores y alumnos de la Facultad de Ciencias Políticas y Sociología, recurrimos a un ejemplo cercano de otro eje discursivo muy presente en la memoria española del Holocausto: el sufrimiento palestino codificado en términos del genocidio judío y la demanda de su memoria en igualdad de condiciones. Estamos ante otro ejemplo de la fuerza simbólica del Holocausto que como término ya universalizado del mal radical y del máximo oprobio moral invita a su uso retórico como poderosa metáfora proyectiva para otos acontecimientos, pretéritos o actuales. La diferencia importante es que ahora se otorga a las antiguas víctimas (judíos, Israel) la identidad de los victimarios y que la formulación no surge como equivalencia funcional del propio sufrimiento (como en las víctimas de Franco), sino del de otros. Estas analogías se sitúan en un contexto de sobrerepresentación de términos, símbolos e imágenes del Holocausto en las crónicas, columnas de opinión y caricaturas periodísticas referidas a Israel y el conflicto de Oriente Medio en la prensa española (Baer y Zukermann 2005, Baer 2006, López Alonso 2009). En definitiva, hay una constante asociación discursiva entre una realidad y otra y se produce en ambas direcciones. Como señalaba la escritora Elvira Lindo (2005) en un artículo de EL PAis titulado "El tic", existe un automatismo particularmente español que consiste en "mentar el problema entre israelíes y palestinos cada vez que se habla o escribe sobre las víctimas judías del nazismo o de Auschwitz". En este sentido también es frecuente encontrar la crítica a Israel amalgamada a las iniciativas de memoria del Holocausto. Por ejemplo, un día después de las conmemoraciones por el 60 aniversario de la liberación de Auschwitz, $A B C$ publicaba una viñeta que mostraba a un individuo ataviado con la característica kefia blanquinegra mirando hacia una torreta de vigilancia y un cercado de alambre de espino con la siguiente explicación al pie: "Palestino, comprendiendo el dolor judío por el Holocausto, a partir del asesinato de toda su familia por los israelíes". ${ }^{31}$

El conflicto israelí-palestino como espacio de proyección de analogías y equivalencias del Holo-

\footnotetext{
la historiografía española el debate acerca de cuál de ellos llevó la iniciativa en este aspecto, cuál se vio en la necesidad de reaccionar y cuál fue más sistemático y cruel en el uso de la violencia.

${ }^{31} A B C, 28$ de enero de 2005, p.8.

32 "Ciempozuelos recuerda el "genocidio palestino" el Día del Holocausto Judío". El País, 27 de enero de 2007. La iniciativa del
} 
causto también ha dado lugar a intensas controversias en torno a los actos conmemorativos. Ya nos referimos a la alusión a "los campos de concentración en Palestina" del presidente de la Amical de Mauthausen en la ceremonia de 2005. Otro caso sonado fue el de la iniciativa de algunos ayuntamientos gobernados por la izquierda o el nacionalismo de sustituir los actos de memoria del Holocausto por la memoria del "genocidio palestino" 32 o, como en 2008, la paralización por parte del Bloque Nacionalista Gallego, entonces en gobierno de coalición en la Comunidad Autónoma de Galicia, de una Declaración Institucional de condena al nazismo y en memoria de las víctimas del Holocausto en el Parlamento porque el texto no incluía "el bloqueo que sufre la franja de Gaza o el muro de separación que está construyendo el Estado israelí como parte de la ocupación militar de Palestina". En 2009 el ataque israelí en la franja de Gaza vuelve a situar estas equivalencias acusatorias en primer plano de la opinión española. Una manifestación multitudinaria encabezada por miembros del gobernante partido socialista, sindicatos y artistas con el lema "Paremos el genocidio de Gaza" y otros lemas similares recorrió las calles de las principales ciudades españolas, y estuvo seguida por un aluvión de expresiones e imputaciones en los medios en términos difícilmente imaginables en la prensa europea.

"El cerebro del exterminio de los palestinos no es distinto del que diseñó la Alemania nazi" escribía el periodista Carlos Carnicero en un artículo titulado la "La fecha de caducidad del Holocausto. ${ }^{33} \mathrm{Y}$ el escritor Antonio Gala sentenciaba: "Sin paz, sin límites, sin freno a la avaricia y a las falsas historias, el pueblo judío sucumbirá de nuevo (...) ¿No haría bien preguntándose el porqué le ocurre siempre igual? ¿O estará el resto del mundo siembre equivocado?"34 Algunos artículos se hicieron eco del progresivo y evidente desliz hacia el terreno del antisemitismo y señalaron que lo que ocurría en España no se explicaba por la sola indignación humanitaria ante las acciones israelíes. ¿Por qué en la España de la corrección política, donde un nimio matiz retórico o un chiste que haga mofa de las minorías protegidas te condenan a la caverna, es posible avalar el Holocausto y volverlo contra quienes lo sufrieron sin que ocurra nada?" escribía David Gistau en respuesta a Gala en El Mundo, el 8 de febrero de 2009). Igualmente, un editorial del diario La Vanguardia titulado "Antijudaísmo, lo que no puede ser" señalaba que "Gaza tensa los ánimos y los sentimientos, convoca la crítica y la protesta, pero la relativización del holocausto (...) y la siniestra reaparición del antijudaísmo son inadmisibles". ${ }^{35}$ El conflicto de Gaza, o mejor dicho su repercusión en los medios españoles, afectó sensiblemente a las conmemoraciones oficiales del Holocausto (en Melilla no se celebraron y en Cataluña se suspendieron los actos públicos, pero se celebraron los oficiales en la sede de la Generalitat a puerta cerrada). En Madrid se realizó el acto de Estado, aunque en la entrada del recinto un grupo de 20 activistas, convocados por el mencionado Colectivo celebró una concentración con pancartas en las que se podía leer la definición de Holocausto y a continuación: “¿Y qué está pasando en Gaza?”.

Lo expuesto muestra un conjunto de motivos asociados al discurso sobre el Holocausto muy extendidos en España. El propio término remite hoy - al menos en un amplio sector de los marcadores de opinión pública española - a asociaciones sobre "victimismo judío", "apropiación con fines espurios" y el "Holocausto palestino". Y a diferencia de otros países de Europa estos discursos no son marginales sino mainstream. Como escribía el escritor y periodista Enric Juliana (2009) en una serie de artículos en La Vanguardia bajo la rúbrica España e Israel, "un político europeo se lo pensará dos o tres veces antes de acompañar una manifestación que concluya con la quema de la estrella de David". Y, podemos añadir, un director de periódico europeo sentirá cierta aprensión a publicar una viñeta objetivamente antisemita. En España "la memoria del Holocausto es débil", concluye Juliana, y por lo tanto, "tanto da". Nos encontramos ante la parado-

\footnotetext{
ayuntamiento de Ciempozuelos (Madrid) “recibió las críticas del embajador de Israel y de las comunidades judías de España, así como del PP. Para IU, es compatible "el homenaje a todos los holocaustos".

${ }^{33}$ El Plural.com, 4 de enero de 2009.

${ }^{34} \mathrm{El} \mathrm{Mundo,} 6$ de febrero de 2009. Gonzalo Álvarez Chillida ya señala a Antonio Gala como un escritor de la "intelectualidad progresista" que en sus novelas "refleja algunos de los elementos del antisemitismo más tradicional" (2002: 470).

${ }^{35}$ La Vanguardia, 15 de enero de 2009.
} 
ja de una notoria falta de cultura del Holocausto en el contexto de un cada vez más presente discurso globalizado sobre el Holocausto. Por ello, en torno al lugar común "Holocausto" y con el trasfondo del conflicto israelí-palestino se articulan en España discursos activadores de una nada desdeñable hostilidad antisemita.

\section{CONCLUSIÓN: LA HUELLA DE SEFARAD}

Tras este recorrido, podemos volver a la pregunta inicial sobre el vínculo de España con la memoria del Holocausto. Que este vínculo sea débil no se debe a la - relativa - distancia con los hechos históricos del genocidio de los judíos de Europa. Es más bien una consecuencia de la particular recepción de esos hechos a partir de 1945 en un país prácticamente judenrein desde hacía cinco siglos. Son en gran medida los vacíos, silencios y también persistentes prejuicios sobre lo judío (que se avivan en la dictadura pero que no desaparecen en la democracia) los que configuran en términos sociológicos la actividad discursiva sobre el Holocausto en la España contemporánea.

Existen, ciertamente, distintas formas de memoria del Holocausto en España. Tendríamos la memoria que Todorov (1995) entiende como singular o literal (la de los colectivos afectados o directamente aludidos) frente a la universal y ejemplarizante promovida por las instituciones transnacionales, así como los distintos vectores de identificación y proyección de la memoria en relación a otros hechos de violencia. Habría, tal vez una aproximación al Holocausto que nos devuelve al comienzo y al título de este ensayo: la huella olvidada de Sefarad. Sería ésta una memoria del Holocausto específicamente española que permite una reflexión crítica sobre el presente en la medida que, como sostiene Walter Benjamin, el presente puede ser iluminado en un instante a través de la fuerza fugaz de un pasado olvidado. En otras palabras, el reconocimiento que el olvido de ese pasado forma parte de la realidad y configura el presente. Por ello, si hubiera que elegir una fecha para la conmemoración, esta iluminación tal vez no la encuentre España en el 27 de enero (memoria universal pero abstracta) y tampoco en el Yom Hashoah o el 5 de mayo (memorias concretas pero particulares - judía y republicana-), sino en el 31 de marzo, la fecha del decreto de expulsión de los judíos promulgado por los Reyes Católicos en 1492; un decreto elogiado y considerado vigente por Franco. ${ }^{36}$

En la España del siglo XXI es muy frecuente invocar la "España de las tres culturas", una suerte de mito de origen que inspira una supuesta innata tolerancia hispana. Pero, como escribe Reyes Mate, no podemos reivindicar aquella España sin cuestionar la del presente porque "nosotros somos hijos, por vía directa, de la España intolerante" (2008: 142). He aquí un extraordinario vínculo con una memoria del Holocausto particularmente española. Franco, no es necesario recordarlo, se inscribe en la estela de la España intolerante, por lo que Sefarad y la República pueden ser memorias entreveradas. La República estrechó lazos con las comunidades sefardíes del Protectorado de Marruecos y los Balcanes y aprobó una legislación de libertad religiosa sin precedentes. Liberales y progresistas republicanos encarnaban la antítesis del nacionalismo y conservadurismo clerical que relegaría lo judío nuevamente al olvido y que marcaría a la sociedad española por décadas. Al igual que estos vacíos y lastres condicionan las formas de recordar el Holocausto en la España actual, una memoria del Holocausto española que tenga en cuenta la memoria de Sefarad puede llegar, como sugiere Benjamin, a iluminar el presente.

\footnotetext{
${ }^{36}$ En su mensaje de fin de año de 1938, Franco justifica las acciones antisemitas nazis y en relación a ello añade: "Nosotros, que por la gracia de Dios y la clara visión de los Reyes Católicos, hace siglos nos liberamos de tan pesada carga" (citado en Álvarez Chillida, 2002: 398).
} 


\section{BIBLIOGRAFÍA}

AleXANDER, Jeffrey (2002): "On the Social Construction of Moral Universals. The 'Holocaust' from War Crime to Trauma Drama.” European Journal of Social Theory 5(1): 5-85.

Alvarez Chillida, Gonzalo (2002): El antisemitismo en España. La imagen del judio (1812-2002). Madrid: Marcial Pons.

Armengou, Montse y Ricard Belis (2005): El convoy de los 927. Barcelona: Plaza y Janés.

Armengou, Montse y Ricard Belis (2005): Las fosas del silencio ¿Hay un Holocausto español? Barcelona: Debolsillo.

AvnI, Haim (1982): España, Franco y los judios. Madrid: Altalena.

Avn, Haim (2003): “La Guerra y las posibilidades de rescate.” En Milgram, Avraham (ed.) Entre la aceptación y el rechazo. América Latina y los refugiados del nazismo. Jerusalem: Yad Vashem.

BAER, Alejandro (2009): Visados para la Libertad. Diplomáticos españoles ante el Holocausto (Catálogo de Exposición). Madrid: Ministerio de Exteriores y Cooperación y Casa Sefarad Israel.

BAER, Alejandro (2006): Holocausto. Recuerdo y representación. Madrid: Losada.

BAER, Alejandro y Federico ZuKIERMAn (2005): “Israel y el judaísmo en el humor gráfico Español (2000-2003).” En: Israel Garzón, Jacobo (ed.) El estigma imborrable: reflexiones sobre el nuevo antisemitismo. Madrid: Hebraica Ediciones.

Benasuly, Alberto (1999): "Bofetada al oro nazi”. Boletín Gueshernews, n 2.

CALVET, Josep (2008): Les muntanyes de la llibertat. Barcelona: L'Avenç.

Espinosa, Francico (2003): La columna de la muerte: el avance del ejército franquista de Sevilla a Badajoz. Barcelona: Crírica.

Fernández, Antonio (1988) Historia del Mundo Contemporáno. Madrid: Vicens-Vives.

FERRÁndiz, Francisco y Alejandro BAER (2008): "Digital Memory: The Visual Recording of Mass Grave Exhumations in Contemporary Spain". Forum Qualitative Sozialforschung /Special Issue Visual Methods 9(3).

FERRÁNDIZ, Francisco (2007): "Exhumaciones y políticas de la memoria en la España contemporánea." Hispania Nova (7).

GALLEGO, Ferrán (2008): “La España de Franco y el Holocausto. Otra zona para la memoria y la educación.” En Forges, Jean Francois (ed) Educar contra Auschwitz. Historia y memoria. Barcelona: Anthropos.

Halbwachs, Maurice (1968): La mémorie collective. Paris: Press Universitaires de France. La memoria colectiva. Zaragoza: Prensas Universitarias de Zaragoza (2004).

HARTMAN, Geoffrey (2002): The Longest Shadow. In the Aftermath of the Holocaust. Indiana: Indiana University Press.

Huyssen, Andreas (2002): En busca del futuro perdido. Cultura y memoria en tiempos de globalización. México: Fondo de Cultura Económica.

IsRael Garzón, Jacobo y Alejandro Baer (2007): España y el Holocausto. Historia y testimonios. Madrid: Hebraica Ediciones.

JuliÁ, SAntos (2003): "Echar al olvido: Memoria y amnistía en la transición." Claves de Razón Práctica (129): 14-25.

JulianA, EnRic (2009): "España e Israel”. La Vanguardia, 10 de enero de 2009.

Levy, Daniel y Natan SzNAider (2002): "The Holocaust and the Formation of Cosmopolitan Memory." European Journal of Social Theory 5(1): 87-206.

Lindo, Elvira. "El TIC", EL PAiS, 2 de febrero de 2005.

LisBona, José Antonio (2002): España-Israel. Historia de unas relaciones secretas. Madrid: Temas de Hoy.

Lopez Alonso, Carmen (2007): La evolución de la prensa española con relación a Israel, el antisemitismo y el conflicto árabe-israelo-palestino. En Rein, Raanan (ed.) España e Israel veinte años después. Madrid: Dykinson.

Marinas, Jose Miguel (2000): “Como cantar en tierra extraña.” Isegoría (23): 139-153.

Marquina, Antonio y Ines Ospina (1987): Espana y los judios en el siglo XX. Madrid: Espasa Calpe.

MATE, Reyes (2008): La herencia del olvido. Madrid: Errata Naturae.

Mate, Reyes (2006) "Presentación". En: Baer, Alejandro, Holocausto. Recuerdo y Representación. Madrid: Losada.

Moa, Pío. "Santos Juliá defiende a 'los pobres', Libertad Digital (www.libertaddigital.com) 22 de noviembre de 2007.

Muñoz Molina, Antonio (2006) "Notas escépticas de un republicano”, El PAís, 24 de abril.

PABÓn, Carlos (2009): “QQué es genocidio? Problemas, límites y retos de un concepto crucial de nuestro tiempo”, artículo sin publicar.

RodRIGO, Javier (2003): “1936: Guerra de exterminio, genocidio, exclusión.” Historia y Politica (10): 249-258.

Rother, Bernd (2004): Franco y el Holocausto. Madrid: Marcial Pons. 
RothberG, Michael (2009): Multidirectional Memory: Remembering the Holocaust in the age of decolonization. Stanford: Stanford University Press.

Rozenberg, Danielle (2006): L'Espagne contemporaine et la question juive. Toulouse: Presses Univeritaires du Mirail. Stallaert, Christiane (2006): Ni una gota de sangre impura. La España inquisitorial y la Alemania nazi cara a cara. Barcelona: Galaxia Gutenberg/Círculo de Lectores.

Todorov, Tzvetan (1995): Los abusos de la memoria. Barcelona: Paidós. 